\title{
Cell proliferation and apoptosis in the fetal and neonatal ovary of guinea pigs
}

\author{
S.Y. Sun ${ }^{1,2}$, W. Zhang ${ }^{1,3}$, X. Han ${ }^{1}$, R.H. Huang ${ }^{1}$ and F.X. Shi ${ }^{1}$ \\ ${ }^{1}$ Laboratory of Animal Reproduction, College of Animal Science and Technology, \\ Nanjing Agricultural University, Nanjing, China \\ ${ }^{2}$ Wenzhou Vocational College of Science and Technology, Wenzhou, China \\ ${ }^{3}$ College of Animal Science, Henan Science and Technology Institute, \\ Xinxiang, China \\ Corresponding authors: F.X. Shi / R.H. Huang \\ E-mail: fxshi@njau.edu.cn / hrh2002@126.com
}

Genet. Mol. Res. 13 (1): 1570-1578 (2014)

Received January 18, 2013

Accepted June 29, 2013

Published March 12, 2014

DOI http://dx.doi.org/10.4238/2014.March.12.9

\begin{abstract}
The guinea pig is an excellent animal model for studying reproductive biology of adult humans and most domestic animals. Yet, whether this animal might serve as a good model for embryonic stage investigations and determinations of signals affecting or directing ovary development remains unknown. These questions were addressed by examining morphological evolution and the expression of biomarkers of cell proliferation and apoptosis in the ovaries of fetal and neonatal guinea pigs in the present study. Embryonic and neonatal guinea pigs at $30,40,50,60$, and 68 days postcoitum (dpc) and at 1 day postpartum (dpp) were evaluated, and the dynamic changes in follicles between $30 \mathrm{dpc}$ and $1 \mathrm{dpp}$ were observed. Results also showed that a critical period of follicular development in guinea pig embryos occurred at 40 to $50 \mathrm{dpc}$. Moreover, the proliferating-cell nuclear antigen, a cell proliferation marker, immunohistochemically stained healthy follicles, while caspase-3, an apoptosis marker, was mainly observed in atretic follicles. Together, these results demonstrate that cell proliferation and apoptosis contribute to follicular formation, development, and atresia in fetal and neonatal guinea pig ovaries. Furthermore, this study
\end{abstract}


confirmed that the guinea pig is also an excellent animal model for studying reproductive biology in human and domestic animal embryos.

Key words: Cell proliferation; Apoptosis; Ovary; Embryo; Guinea pig

\section{INTRODUCTION}

Guinea pigs, unlike other rodents, i.e., rats, mice and hamsters, exhibit follicular formation and development in utero before birth, and thus have a long gestation period of approximately 70 days, similar to that of large animals (Shi et al., 1999; Suzuki et al., 2003; Sadeu et al., 2007). During pregnancy, fetal ovarian development begins with primordial germ cells (PGCs) migrating to and invading embryonic gonads, followed by primordial follicle assembly and development at different time points (Loffler and Koopman, 2002; Suh et al., 2002; Sawyer et al., 2002). Additionally, the number of oocytes in the adult animal ovary is dependent on the initial recruitment of primordial follicles (McGee and Hsueh, 2000). Therefore, understanding changes and the mechanisms underlying embryo ovarian development during pregnancy has become increasingly critical.

During the embryonic ovarian development process, on the one hand, cell proliferation (especially that of granulosa cells) is important for follicle assembly and development (van den Hurk and Zhao, 2005). In addition, apoptosis has been implicated in processes associated with normal ovarian development and function, including death of germ and granulosa cells in follicular atresia (Morita and Tilly, 1999; Tilly and Robles, 1999). Several previous studies have investigated morphological changes of ovaries in young and adult guinea pigs (Bookhout, 1945; Sadeu et al., 2007; Wang et al., 2010). However, such knowledge with respect to embryonic guinea pigs is lacking. Moreover, no metabolic markers have yet been examined in these embryos. In this study, we addressed not only morphological changes, but also changes in the expression of metabolic markers, in the ovary of embryonic guinea pigs. We used proliferating-cell nuclear antigen (PCNA) as a proliferation marker and caspase-3 as an apoptosis marker. PCNA is a co-factor of DNA polymerases, and plays a key role in controlling several reactions involved in cell proliferation (Maga and Hubscher, 2003; Moldovan et al., 2007). Therefore, this protein has been commonly used as a proliferation marker (Paunesku et al., 2001; Sears and Nevins, 2002; Wildemann et al., 2003). Caspases (cysteine proteases) underlie the metabolic and morphological features of apoptosis. Among them, caspase-3 is a major executioner protease, participating in cell apoptosis during follicular atresia (Matikainen et al., 2001; Johnson and Bridgham, 2002; Glamočlija et al., 2005; Hussein, 2005).

Therefore, the present study was designed to investigate follicular formation and development, and to examine the ovarian expression of PCNA and caspase- 3 in embryonic and neonatal guinea pigs.

\section{MATERIAL AND METHODS}

\section{Animals and sample collection}

Adult guinea pigs (Cavia porcellus) of the Hartley strain of 5 months of age, with an initial weight of 400-700 g, were provided by the Experimental Animal Center of Nanjing Medical University (Nanjing, China). Four animals per cage were housed under a temperature of $23^{\circ}$ 
$\pm 2^{\circ} \mathrm{C}$ and $50 \pm 20 \%$ humidity with a 12 -h light and dark cycle, and were fed commercial food and tap water ad libitum. The cages used for breeding guinea pigs in this study were $75 \times 75 \times 30$ $\mathrm{cm}^{3}$ and were purchased from the Experimental Animal Center of Nanjing Medical University (Nanjing, China). Bedding was replaced every week. The estrous cycles of parental females were examined daily, checked when vaginas were open from 1 week prior to mating, and parental males were randomly paired with an equivalently treated female (1:1 ratio). Fetal guinea pig ovaries from pregnant gilts $(\mathrm{N}=5)$ were obtained by hysterotomy performed under anesthesia with isoflurane (Foranew, Abbott Japan Co., Ltd., Tokyo, Japan) 30, 40, 50, 60, and 68 days postcoitum (dpc). Neonatal guinea pig ovaries from neonatal pups were obtained by ovariectomy performed under isoflurane anesthesia 1 day postpartum (dpp). Briefly, pregnant female guinea pigs were anaesthetized with 5\% isoflurane, which was delivered during induction, and with $1-2 \%$ isoflurane via a facemask during surgery. The skin on the genital pore and the abdomen was then clipped and disinfected. Pregnant animals were then placed in dorsal recumbency, and fetal guinea pigs were obtained using an aseptic technique. The animal was treated gently, and surgery time for each animal was limited to $1 \mathrm{~h}$. The animal experimental protocol was approved by the Institutional Animal Care and Use Committee of Nanjing Agricultural University, and experiments were strictly carried out according to appropriate animal welfare guidelines (Close et al., 1996).

\section{Histological observations}

To evaluate the follicular formation and development of female fetal and neonatal guinea pigs, ovarian samples kept in $70 \%$ alcohol were dehydrated through increasing alcohol concentrations, embedded in paraffin, and sectioned serially at $5 \mu \mathrm{m}$. Ten slides were randomly chosen at every time point, stained with hematoxylin and eosin, and histopathology was observed under a light microscope (Nikon Inc., Melville, NY, USA).

\section{Determination of germ cell number and follicle classification}

The numbers of individual follicles and egg nests were determined by examining five sections (the middle cross-section and four other sections) per ovary. Every section was at least $20 \mu \mathrm{m}$ away from other sections. Egg nests were classified as oogonia or oocytes clustered into nests and surrounded by a layer of squamous follicular cells as described previously (McCoard et al., 2003; Kezele and Skinner, 2003). Primordial follicle classification was based on the presence of a single layer of flattened follicular cells surrounding an individual oocyte. An oocyte surrounded by a single layer of cuboidal follicular cells was classified as a primary follicle. Secondary follicles had more than one distinct layer of cuboidal granulosa cells.

\section{Immunohistological staining}

After fixation, ovaries from female fetal and neonatal guinea pigs at different time points were embedded in paraffin, and then $5-\mu \mathrm{m}$ sections were cut and mounted on slides. The sections were then processed for immunohistochemical analysis using polyclonal antibodies raised in rabbits against PCNA and caspase-3 (Boster Biological Technology, Ltd. Co., Wuhan, China). The sections were incubated at room temperature overnight with polyclonal rabbit immunoaffinity-purified antisera directed against PCNA (1:100) or caspase-3 (1:100). The 
immunoreactivity assay of specific proteins was visualized by the Elite ABC kit (BioGenex, San Ramon, CA, USA), and reactions were performed with $0.05 \%$ 3,3'-diaminobenzidine tetrachloride (Sigma Chemical Co., USA) in $10 \mathrm{mM}$ phosphate-buffered saline containing $0.01 \% \mathrm{H}_{2} \mathrm{O}_{2}$ for $3 \mathrm{~min}$. The negative control used normal rabbit serum instead of primary antibody (Boster Biological Technology). Finally, sections were counter-stained with hematoxylin and mounted with coverslips to identify the structure and type of cells.

\section{Statistical analysis}

Statistical analyses were performed using the Statistical Package for the Social Sciences (SPSS) program. Differences in percentage of egg nests, single follicles, and types of follicles between ages were evaluated by one-way analyses of variance (ANOVA) with Tukey tests. P values less than 0.05 were considered to be statistically significant.

\section{RESULTS}

\section{Morphological changes during follicular formation and development in female fetal and neonatal guinea pigs}

Follicular formation and development in female fetal and neonatal guinea pigs were evaluated in ovaries at 30, 40,50,60, and $68 \mathrm{dpc}$ and at $1 \mathrm{dpp}$. At $30 \mathrm{dpc}$, the fetal ovary was comprised primarily of naked eggs not yet assembled into primordial follicles; these oocytes were located in nests within the ovarian cortex (Figure 1A). In the 40-dpc-old ovary, the vast majority of follicles were primordial follicles, and the largest follicles observed contained a single layer of granulosa cells (Figure 1B). In addition, at $50 \mathrm{dpc}$, primordial and primary follicles were present in the cortex in multiple layers; secondary follicles were first observed and located at the innermost cortical-medullary border (Figure 1C). At $60 \mathrm{dpc}$, secondary follicles with two or more layers of squamous granulosa cells appeared (Figure 1D). At $68 \mathrm{dpc}$, before parturition, oocytes in the largest early tertiary follicles with antra were surrounded by more than three layers of squamous granulosa cells (Figure 1E). At $1 \mathrm{dpp}$, ovarian contents were observed to be identical to those at $68 \mathrm{dpc}$ (Figure 1F).

\section{Primordial follicle assembly and developmental kinetics}

By $50 \mathrm{dpc}$, the proportion of egg nests, which included unassembled oocytes, decreased to only $35.2 \%$, and continuously decreased to $15.2,5.7$, and 4.8 at $60 \mathrm{dpc}, 68 \mathrm{dpc}$, and $1 \mathrm{dpp}$, respectively $(\mathrm{P}<0.001$; Figure $2 \mathrm{~A})$. Furthermore, there was a gradual increase in the primordial to primary follicle transition, with the percentage of different-stage follicles comprising $64.8 \%$ of all single follicles; single follicles comprised approximately $95 \%$ at $1 \mathrm{dpp}$ (Figure 2A). In addition, primordial follicles were not observed at $30 \mathrm{dpc}$, and the proportions of primordial follicles increased between 40 and $50 \mathrm{dpc}(\mathrm{P}<0.05)$ but decreased $(\mathrm{P}<0.05)$ from $60 \mathrm{dpc}$ to $1 \mathrm{dpp}$ (Figure 2B). The proportions of primary follicles increased from $50 \mathrm{dpc}$ to $1 \mathrm{dpp}(\mathrm{P}<0.05$; Figure $2 \mathrm{~B})$. Secondary follicles were frequently observed at $68 \mathrm{dpc}$ and beyond. Consistent with directional transition in follicle development, secondary follicles were always located at the cortical-medullary border forming a layer inside the primary follicles. 


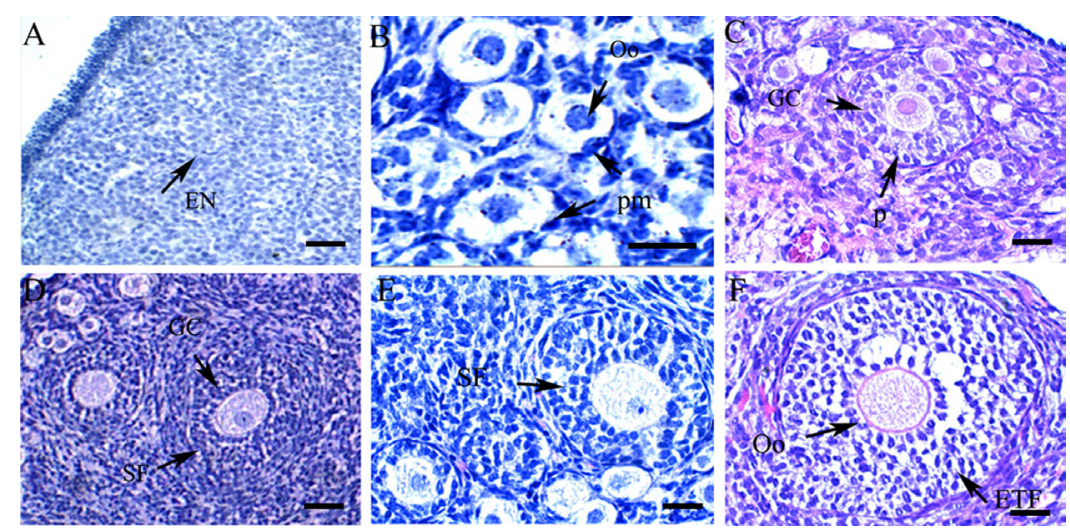

Figure 1. Histologic observation of follicular formation and development in female fetal and neonatal guinea pigs. A. 30 days postcoitum (dpc). B. 40 dpc. C. 50 dpc. D. 60 dpc. E. 68 dpc. F. 1 day postpartum (dpp). EN = egg nest; $\mathrm{pm}$ : primordial follicle; $\mathrm{p}=$ primary follicle; $\mathrm{SF}=$ secondary follicle; $\mathrm{ETF}=$ early tertiary follicle; $\mathrm{GC}=$ granulosa cell; Oo $=$ oocyte. Scale bars $=50 \mu \mathrm{m}$.

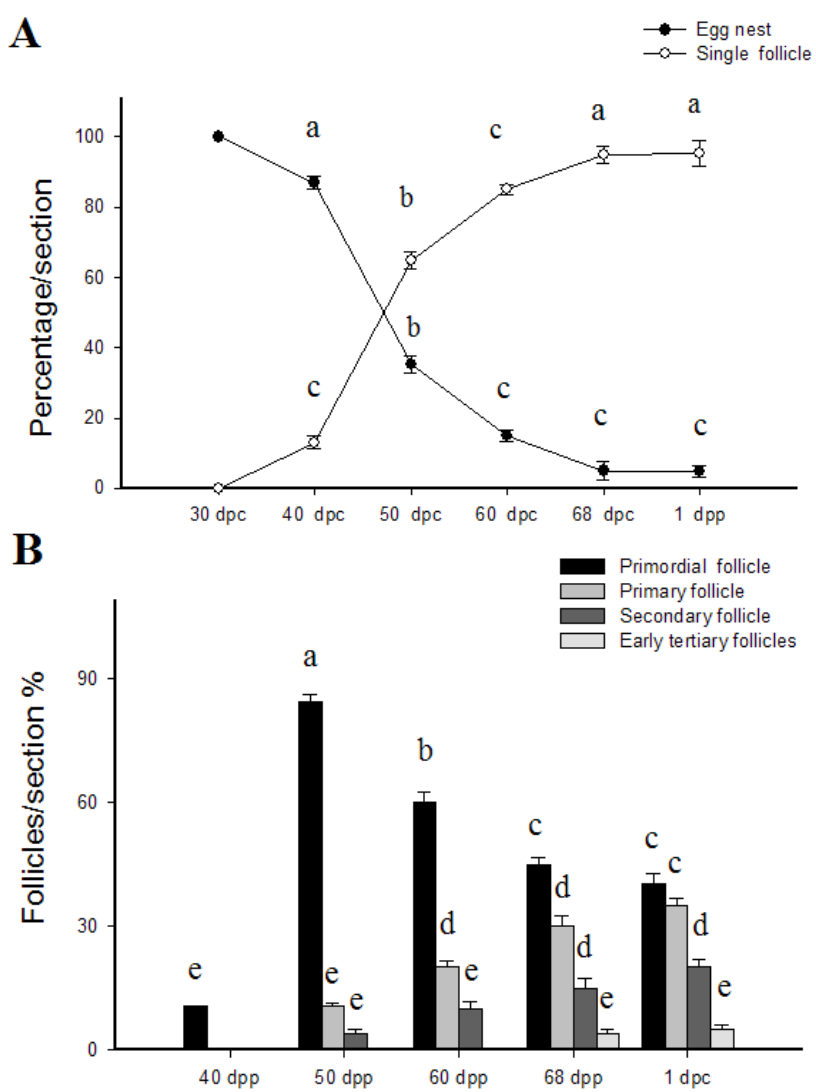

Figure 2. Percentages of egg nests and follicles per section in the fetal and neonatal guinea pig ovary. A. Percentages of egg nests and single follicles; B. percentages of primordial and primary follicles. $\mathrm{dpc}=$ day postcoitum; $\mathrm{dpp}=\mathrm{day}$ postpartum. Values represent means $\pm \mathrm{SE}$. Bars with different superscript letters are statistically different. $\mathrm{P}<0.05$. 


\section{Immunohistochemical analysis of PCNA and caspase-3}

To investigate the localization of PCNA and caspase-3 proteins, markers of cell proliferation and apoptosis in the ovary during follicular development in fetal and neonatal guinea pigs, immunohistochemical analysis was performed in the ovaries at 30,40,50,60, $68 \mathrm{dpc}$, and at $1 \mathrm{dpp}$. Results showed that the PCNA was mainly localized in oocytes and in some stromal cells between different nests at $30 \mathrm{dpc}$ (Figure 3A). At $40 \mathrm{dpc}$, oocytes and the single layer of granulosa cells of primordial follicles were strongly stained (Figure 3B). The staining of PCNA expanded through multiple layers of granulosa cells, which accompanied follicular development at 50 and $60 \mathrm{dpc}$ (Figure 3C and D). In addition, PCNA was also expressed at the surface of epithelial cells (Figure 3C). Furthermore, at $68 \mathrm{dpc}$ and at $1 \mathrm{dpp}$, the expression patterns were the same as those at 50 and $60 \mathrm{dpc}$, localizing to secondary follicles, early tertiary follicles, and some stromal cells (Figure 3E and F).

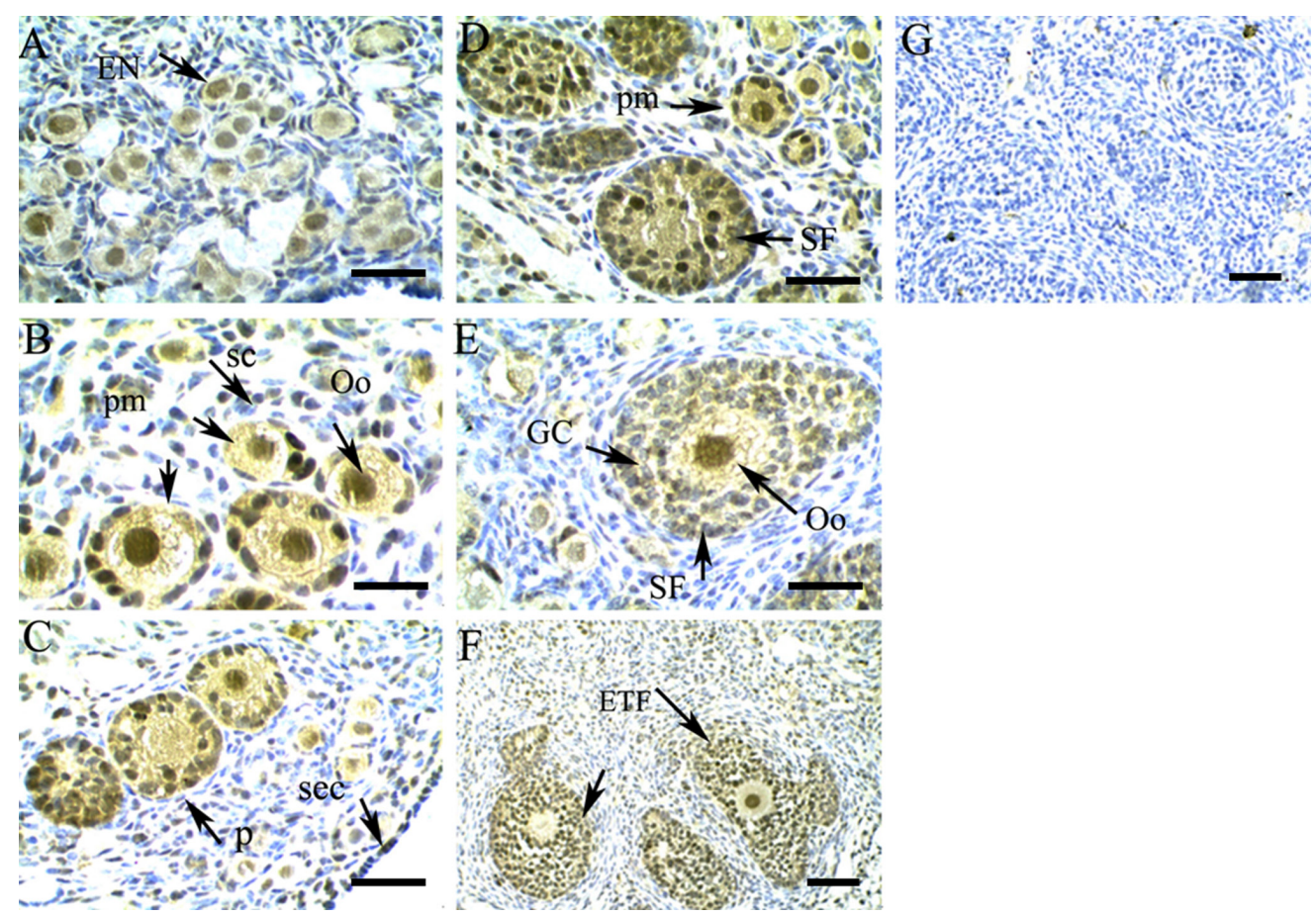

Figure 3. Immunohistochemical analysis of PCNA. Ovarian sections were immunohistochemical stained for PCNA and counterstained with H\&E. The immunohistochemical signals appear brown and the counterstaining background was blue in color. A. 30 days postcoitum (dpc). B. 40 dpc. C. 50 dpc. D. 60 dpc. E. 68 dpc. F. 1 day postpartum (dpp). G. Negative control. $\mathrm{EN}=$ egg nest; $\mathrm{pm}=$ primordial follicle; $\mathrm{p}=$ primary follicle; $\mathrm{sc}=$ stromal cells; $\mathrm{sec}=$ superficial epidermal cells; $\mathrm{SF}=$ secondary follicle; $\mathrm{ETF}=$ early tertiary follicle; $\mathrm{GC}=$ granulosa cell; Oo = oocyte. Scale bars $=50 \mu \mathrm{m}$.

We further evaluated changes and expression patterns of caspase- 3 during follicular formation and development in fetal and neonatal guinea pigs. At $30 \mathrm{dpc}$, caspase- 3 was mainly localized in some oocytes and stromal cells among different nests. In addition, some oocytes 
that did not stain for caspase-3 were located near the positively stained parts of the egg nest (Figure 4A). At 40 and $50 \mathrm{dpc}$, caspase-3 staining was localized to oocytes and expanded through layers of granulosa cells (Figure 4B and C). Caspase-3 was also expressed at the surface of epithelial cells (Figure 4B). Furthermore, positive staining of caspase-3 was observed in oocytes and granulosa cells of atretic follicles at $60 \mathrm{dpc}, 68 \mathrm{dpc}$, and $1 \mathrm{dpp}$ (Figure 4D, E and F). A mass of dead granulosa cells separated from the layer of healthy granulosa cells and scattered in the antrum was found with intensive staining of caspase-3.

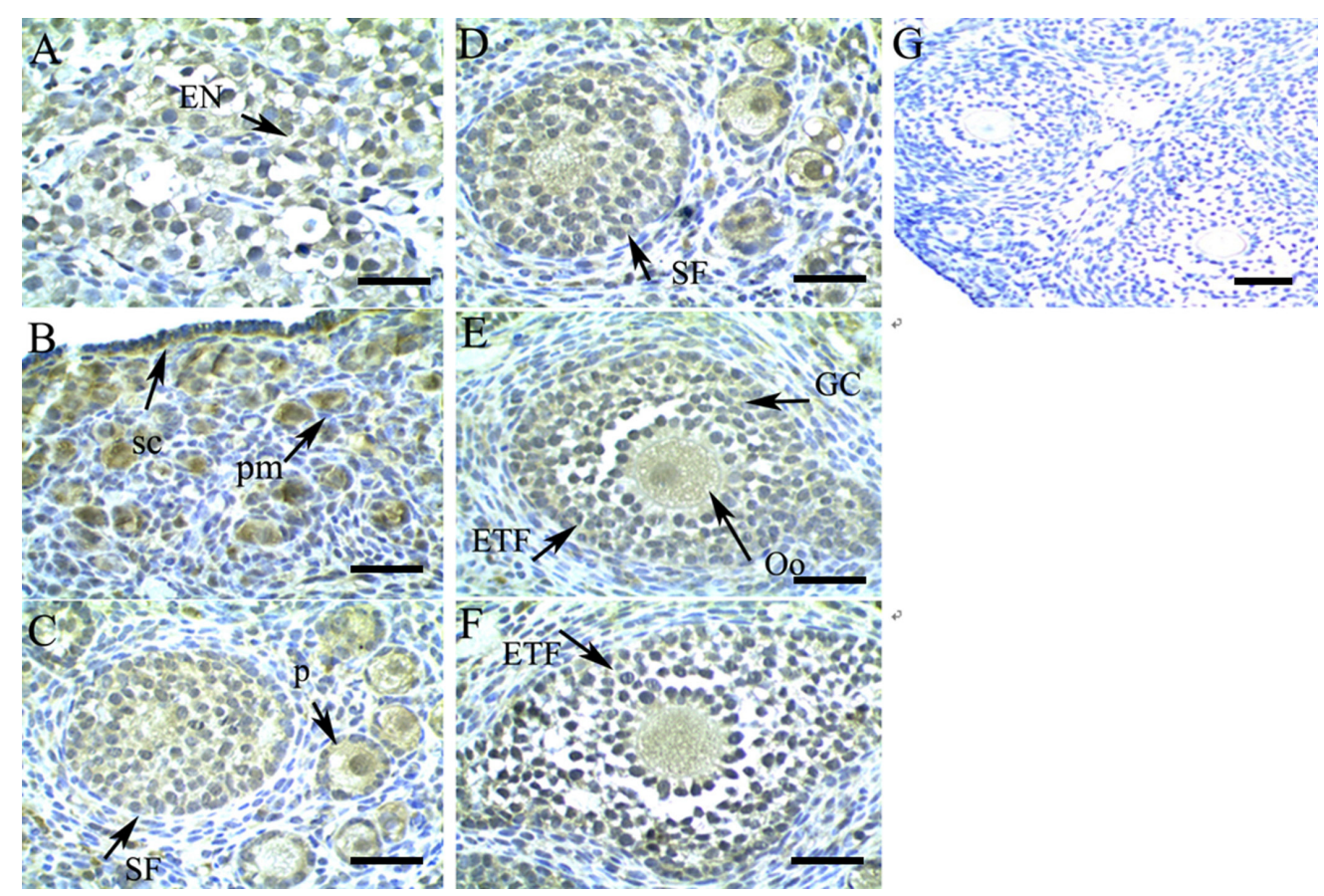

Figure 4. Immunohistochemical analysis of caspase-3. A. 30 days postcoitum (dpc). B. 40 dpc. C. 50 dpc. D. 60 dpc. E. 68 dpc. F. 1 day postpartum (dpp). G. Negative control. EN = egg nests; pm: primordial follicle; p = primary follicle; $\mathrm{sc}=$ stromal cells; $\mathrm{SF}=$ secondary follicle; $\mathrm{ETF}=$ early tertiary follicle; $\mathrm{GC}=$ granulosa cell; $\mathrm{Oo}=$ oocyte. Scale bars $=50 \mu \mathrm{m}$.

\section{DISCUSSION}

To the best of our knowledge, this is the first report showing the morphological changes during follicular formation and the development and expression patterns of PCNA and caspase- 3 in embryonic ovaries from guinea pigs. Our results suggested that the most critical time period of follicular development in guinea pig embryos occurs at 40-50 dpc.

The guinea pig is an excellent animal model for studies of the reproductive system of adult humans and most domestic animals (Suzuki et al., 2003). In mice and rats, comparable studies have revealed that follicular formation and development are initiated after birth (McGee and Hsueh, 2000). In 1945, Bookhout found that guinea pigs initiated their ovarian follicular formation and development before birth (during pregnancy). Results of the present study indicate that primordial follicle assembly and developmental kinetics in guinea pigs are 
similar to embryos of humans, pigs, and sheep (McGee and Hsueh, 2000; Sawyer et al., 2002; Ding et al., 2010). This suggests that the guinea pig is also a good animal model to study early ovarian development in large animals and humans.

Much evidence has accumulated showing an intimate relationship between cell proliferation within oocytes or granulosa cells and follicular development (Matsumi et al., 1998; Quirk et al., 2004; van den Hurk and Zhao, 2005). To confirm this, we investigated PCNA localization in different stages of embryos. We found PCNA continually expressed in oocytes and expanding granulosa cells at 40, 50, 60, and $68 \mathrm{dpc}$, and at $1 \mathrm{dpp}$. Immunohistochemical staining was particularly strong when accompanied by follicular development in healthy follicles. In addition, PCNA was observed in some stromal cells at $30 \mathrm{dpc}$, suggesting that stromal cells were involved in follicular formation.

We also detected the expression pattern of caspase-3 in fetal female guinea pigs. Previous studies reported that caspase- 3 was absent in granulosa cells of healthy follicles and its expression was regulated by gonadotropin in granulosa cells (Boone and Tsang, 1998; Glamočlija et al., 2005). Caspase-3 mutant female mice possessed aberrant atretic follicles containing granulosa cells that could not be eliminated by apoptosis (Matikainen et al., 2001; Johnson and Bridgham, 2002; Quirk et al., 2004; Hussein, 2005). In the present study, we found that caspase- 3 was localized to some oocytes and stromal cells within different nests at $30 \mathrm{dpc}$, and was markedly and continually expressed in oocytes and expanding granulosa cells at 40,50, 60, and $68 \mathrm{dpc}$ and at $1 \mathrm{dpp}$ in atretic follicles; however, it was absent in granulosa cells of healthy follicles. Therefore, caspase-3 appears to be functionally required for granulosa cell apoptosis during follicular atresia in fetal guinea pig ovaries. However, in mice, prepubertal primordial follicle loss was found to occur independently of the classical caspase-3-dependent apoptotic pathway (Tingen et al., 2009). This difference could be due to differences in the follicular environment and might involve some unknown factors.

Both of these criteria were used to evaluate the effects of drugs on developmental and reproductive function (Jacquet et al., 1997; Adriaens et al., 1999; Wehner et al., 2009). Therefore, our findings could help to clarify mechanisms involved in human embryonic ovarian development and folliculogenesis.

Collectively, we expect that in addition to providing information regarding proliferation and apoptosis in guinea pig ovaries during pregnancy in vivo, this study will influence the development of strategies to treat human ovarian cancers and ameliorate adverse effects of their therapy.

\section{ACKNOWLEDGMENTS}

We are grateful to Dr. Ronghua ZhuGe of the University of Massachusetts Medical School and Dr. Reinhold J. Hutz of the Department of Biological Sciences, University of Wisconsin-Milwaukee, USA, for reading the original manuscript and offering valuable suggestions. Research supported in part by the National Nature Science Foundation of China (\#31172206).

\section{REFERENCES}

Adriaens I, Smitz J and Jacquet P (2009). The current knowledge on radiosensitivity of ovarian follicle development stages. Hum. Reprod. Update. 15: 359-377.

Bookhout CG (1945). The development of the guinea-pig ovary from sexual differentiation to maturity. J. Morphol. 77: 233-265.

Boone DL and Tsang BK (1998). Caspase-3 in the rat ovary: localization and possible role in follicular atresia and luteal 
regression. Biol. Reprod. 58: 1533-1539.

Close B, Banister K, Baumans V, Bernoth EM, et al. (1996). Recommendations for euthanasia of experimental animals: Part 1. DGXI of the European Commission. Lab. Anim. 30: 293-316.

Ding W, Wang W, Zhou B, Zhang W, et al. (2010). Formation of primordial follicles and immunolocalization of PTEN, PKB and FOXO3A proteins in the ovaries of fetal and neonatal pigs. J. Reprod. Dev. 56: 162-168.

Glamočlija V, Vilovic K, Saraga-Babic M, Baranovic A, et al. (2005). Apoptosis and active caspase-3 expression in human granulosa cells. Fertil. Steril. 83: 426-431.

Hussein MR (2005). Apoptosis in the ovary: molecular mechanisms. Hum. Reprod. Update. 11: 162-177.

Jacquet P, de Saint-Georges L, Buset J, Baatout S, et al. (1997). Cytogenetic effects of X-rays in the guinea pig female germ cells. II. The maturing oocyte. Mutat. Res. 391: 193-199.

Johnson AL and Bridgham JT (2002). Caspase-mediated apoptosis in the vertebrate ovary. Reproduction 124: 19-27.

Kezele P and Skinner MK (2003). Regulation of ovarian primordial follicle assembly and development by estrogen and progesterone: endocrine model of follicle assembly. Endocrinology 144: 3329-3337.

Loffler KA and Koopman P (2002). Charting the course of ovarian development in vertebrates. Int. J. Dev. Biol. 46: 503-510.

Maga G and Hubscher U (2003). Proliferating cell nuclear antigen (PCNA): a dancer with many partners. J. Cell Sci. 116: 3051-3060.

Matikainen T, Perez GI, Zheng TS, Kluzak TR, et al. (2001). Caspase-3 gene knockout defines cell lineage specificity for programmed cell death signaling in the ovary. Endocrinology 142: 2468-2480.

Matsumi H, Yano T, Koji T, Ogura T, et al. (1998). Expression and localization of inducible nitric oxide synthase in the rat ovary: a possible involvement of nitric oxide in the follicular development. Biochem. Biophys. Res. Commun. 243: 67-72.

McCoard SA, Wise TH and Ford JJ (2003). Germ cell development in Meishan and White Composite gilts. Anim. Reprod. Sci. 77: 85-105.

McGee EA and Hsueh AJ (2000). Initial and cyclic recruitment of ovarian follicles. Endocr. Rev. 21: 200-214.

Moldovan GL, Pfander B and Jentsch S (2007). PCNA, the maestro of the replication fork. Cell 129: 665-679.

Morita Y and Tilly JL (1999). Oocyte apoptosis: like sand through an hourglass. Dev. Biol. 213: 1-17.

Paunesku T, Mittal S, Protic M, Oryhon J, et al. (2001). Proliferating cell nuclear antigen (PCNA): ringmaster of the genome. Int. J. Radiat. Biol. 77: 1007-1021.

Quirk SM, Cowan RG, Harman RM, Hu CL, et al. (2004). Ovarian follicular growth and atresia: the relationship between cell proliferation and survival. J. Anim. Sci. (E-Suppl 82): E40-E52.

Sadeu JC, Adriaens I, Cortvrindt R and Smitz J (2007). Study of folliculogenesis in vivo in guinea pig. Theriogenology 68: $1228-1239$.

Sawyer HR, Smith P, Heath DA, Juengel JL, et al. (2002). Formation of ovarian follicles during fetal development in sheep. Biol. Reprod. 66: 1134-1150.

Sears RC and Nevins JR (2002). Signaling networks that link cell proliferation and cell fate. J. Biol. Chem. 277: 1161711620.

Shi F, Ozawa M, Komura H, Yang P, et al. (1999). Secretion of ovarian inhibin and its physiologic roles in the regulation of follicle-stimulating hormone secretion during the estrous cycle of the female guinea pig. Biol. Reprod. 60: 78-84.

Suh CS, Sonntag B and Erickson GF (2002). The ovarian life cycle: a contemporary view. Rev. Endocr. Metab. Disord. 3: 5-12.

Suzuki O, Koura M, Noguchi Y, Takano K, et al. (2003). Optimization of superovulation induction by human menopausal gonadotropin in guinea pigs based on follicular waves and FSH-receptor homologies. Mol. Reprod. Dev. 64: 219-225.

Tilly JL and Robles R (1999). Apoptosis and its Impact in Clinical Reproductive Medicine. In: Molecular Biology in Reproductive Medicine (Fauser BCJM, Rutherford AJ, Strauss JF III and Van Steirteghem A, eds.). Parthenon New York, New York, 79-96.

Tingen CM, Bristol-Gould SK, Kiesewetter SE, Wellington JT, et al. (2009). Prepubertal primordial follicle loss in mice is not due to classical apoptotic pathways. Biol. Reprod. 81: 16-25.

van den Hurk R and Zhao J (2005). Formation of mammalian oocytes and their growth, differentiation and maturation within ovarian follicles. Theriogenology 63: 1717-1751.

Wang W, Liu H, Ding W, Gong Y, et al. (2010). Involvement of cell proliferation in the process of follicular atresia in the guinea pig. Tissue Cell 42: 234-241.

Wehner NG, Skov M, Shopp G, Rocca MS, et al. (2009). Effects of natalizumab, an alpha4 integrin inhibitor, on fertility in male and female guinea pigs. Birth Defects Res. B Dev. Reprod. Toxicol. 86: 108-116.

Wildemann B, Schmidmaier G, Ordel S, Stange R, et al. (2003). Cell proliferation and differentiation during fracture healing are influenced by locally applied IGF-I and TGF-beta1: comparison of two proliferation markers, PCNA and BrdU. J. Biomed. Mater. Res. B Appl. Biomater. 65: 150-156. 